\title{
Randomized Control Trial
}

\section{Radiofrequency Thermoablation of the Gasserian Ganglion Versus the Peripheral Branches of the Trigeminal Nerve for Treatment of Trigeminal Neuralgia: A Randomized, Control Trial}

Neerja Bharti, MD, John Sujith, MD, Navneet Singla, Mch, Nidhi B. Panda, MD, and Indu Bala, MD

From: Post Graduate Institute of Medical Education and Research, Anesthesia and Intensive

care

Address Correspondence: Neerja Bharti, MD Post Graduate Institute of Medical Education and Researc $h$ Anesthesia and Intensive care,

Sector 12, Chandigarh, 160012 India

E-mail: bhartineerja@ yahoo.com

Disclaimer: There was no external funding in the preparation of this manuscript.

Conflict of interest: Each author certifies that he or she, or a member of his or her immediate family, has no commercial association

(i.e., consultancies, stock ownership, equity interest, patent/licensing arrangements, etc.) that might pose a conflict of interest in connection

with the submitted manuscript.

Manuscript received: 05-11-2018

Revised manuscript received: o8-16-2018 Accepted for publication: 08-27-2018

Free full manuscript: www. painphysicianjournal. com
Background: Trigeminal neuralgia is the most painful condition of facial pain leading to impairment of routine activities. Although radiofrequency thermoablation (RFT) of the Gasserian ganglion is widely used for the treatment of idiopathic trigeminal neuralgia in patients having ineffective pain relief with medical therapy, the incidence of complications like hypoesthesia, neuroparalytic keratitis, and masticatory muscles weakness is high. Recent case reports have shown the effectiveness of RFT of the peripheral branches of the trigeminal nerve for relief of refractory chronic facial pain conditions including trigeminal neuralgia.

Objectives: This study was conducted to compare the efficacy and safety of RFT of the peripheral branches of the trigeminal nerve with RFT of the Gasserian ganglion for the management of idiopathic trigeminal neuralgia.

Study Design: Prospective, randomized, observer-blinded, clinical trial.

Setting: Tertiary care hospital and medical education and research institute.

Methods: A total of 40 adult patients of idiopathic trigeminal neuralgia were randomly allocated into 2 groups. The control group received RFT of the Gasserian ganglion while the study group received RFT of the peripheral branches of trigeminal nerve. The procedures were performed in the operation room under all aseptic precautions with fluoroscopic guidance. Post-procedure, the patients were assessed for loss of sensation along the nerve distribution and the adequacy of pain relief on the Numerical Rating Scale (NRS). The patients were followed up for 3 month to assess the quality of pain relief by the NRS and the Barrow Neurological Institute (BNI) pain intensity scale. Improvement in pain was considered excellent if patients had complete pain relief without any medication, good if there was significant reduction in pain (>50\%) with or without medication, and poor if there was less than $50 \%$ reduction in pain with medications. Patients were also assessed for numbness and any other side effects. Patients' satisfaction with the procedure was recorded.

Results: Nineteen patients in the control group and 18 in study group had effective pain relief of up to 3 months. Their pain scores were comparable at all time intervals, though the number of patients receiving supplementary medications was more in study group at 2 months $(P=0.015)$. The patients showed overall satisfaction score of $8.5(8-9)$ and $8(7-9)$ in control and study groups respectively. The average procedure duration was 30 (30-38) minutes in the control group and 28 (25-40) minutes in the study group. Most of the patients in both groups had mild numbness after the procedure. One patient in the control group had lower eyelid swelling and another had mild weakness of the masseter muscle, which resolved few days later. No major complication was reported in the study group except for 1 patient who reported local ecchymosis.

Limitations: The main limitation of the study is that the patients and the investigator performing the procedure were not blinded, though the person who assessed the patient during follow-up was blinded to the group assignment. Another limitation is that we could not follow up with the patients after 3 months due to time constraints.

Conclusion: We found that radiofrequency thermoablation of the peripheral branches of the trigeminal nerve is an effective and safe procedure for the management of idiopathic trigeminal neuralgia.

Key words: Idiopathic trigeminal neuralgia, radiofrequency thermoablation, Gasserian ganglion, peripheral nerve branches, pain, trigeminal nerve

Pain Physician 2019: 22:147-154 
T rigeminal neuralgia (TGN) is the most commonly diagnosed form of facial pain which usually occurs after 50 years of age and more frequent in females than males (1). It is defined as brief episodes of severe pain, stabbing in nature, occurring recurrently in the trigeminal nerve distribution. Pain commonly lasts from a few seconds to 2 minutes and may recur between pain-free intervals. Most of the patients complain of a sensitive area on the face which can produce an attack of TGN if touched. Daily activities like brushing teeth, applying cosmetics, encountering a breeze, chewing or talking may trigger severe pain (2).

The pathophysiology of TGN remains unclear. According to the "ignition theory," TGN is the result of abnormalities in the afferent neurones of the trigeminal root or ganglion. Any injury to the axons can make them hyperexcitable, leading to this painful neuropathic condition. Some of the risk factors in developing TGN are multiple sclerosis (MS), increased age, stroke, hypertension, and tumors in the region of the trigeminal nerve root. In Idiopathic Trigeminal Neuralgia (ITGN), vascular compression of the nerve is the usual etiology, while secondary TGN is related to the compression by tumor or MS (3). Treating patients with ITGN is difficult in clinical practice and conservative management usually starts with medications such as carbamazepine or oxcarbazepine in gradually increasing doses (4). However, about $25-30 \%$ of patients either become resistant to the therapy or develops unacceptable side effects of high-dose medications and requires interventional pain management (5).

Among the various interventional pain therapies, radiofrequency thermocoagulation (RFT) of the Gasserian ganglion offers the highest rate of complete pain relief especially for patients with high surgical risk or for patients who are unfit for other procedures (6). Previous studies have shown significant pain relief in more than $90 \%$ of patients with the use of RFT of the Gasserian ganglion (79). However, various complications have been reported on long-term follow-up of these patients including decreased corneal reflex, weakness and paralysis of masseter muscle, anesthesia dolorosa, keratitis, dysesthesia, and transient paralysis of cranial nerves $(8,9)$.

RFT of the peripheral branches of the trigeminal nerve is a minimally invasive and safe procedure. A recent clinical trial (10) evaluating the effectiveness of peripheral division RFT versus conventional RFT for the treatment of first division ITGN, has shown 93\% immediate pain relief in patients receiving RFT of the supraorbital nerve which was comparable to those who un- derwent conventional RFT (95\%). Various sporadic case reports have also shown the effectiveness of RFT of the peripheral branches of the trigeminal nerve for relief of refractory chronic neuropathic facial pain conditions other than TGN (11-13). Therefore, this prospective randomized controlled trial was conducted to evaluate the efficacy and safety of RFT of the peripheral branches of the trigeminal nerve in comparison with RFT of the Gasserian ganglion for the management of ITGN.

\section{Methods}

This prospective, randomized, observer- blinded study was conducted in 40 patients of 20 to 70 years of age, diagnosed with idiopathic trigeminal neuralgia, and complaining of severe pain refractory to oral medications. Patients with unstable cardio-respiratory disorder, coagulation and hematological disorder, psychological disorder, history of drug abuse, and the patients who were non-compliant to follow-up were excluded. After approval from the Institutional Ethics Committee, all participants were properly assessed at a pain clinic of the tertiary care hospital regarding the site, duration, nature, and severity of pain at the time of enrollment. They were asked to rate their severity of perceived pain on a Numeric Rating Scale (NRS) ranging from 0 to 10 , with the zero representing no pain and the 10 representing the worst pain possible. Treatment history was taken regarding the use of all medications including doses, duration, and side effects. Physical examination was performed to rule out any systemic illness or local infection at the injection site. An MRI of the brain was performed to rule out other secondary causes of TGN like multiple sclerosis, neuromas, chordomas, gliomas, lymphomas and other vascular conditions like AV malformation and aneurysms. A written informed consent was taken after explaining the procedure and related risk and benefits. The study was registered with the Clinical Trial Registry (CTRI/2016/12/007576).

The patients were randomly allocated into 2 groups with the use of computer generated random numbers which were kept in opaque envelopes, numbered sequentially, and each envelope was opened by the investigator performing the intervention, in confidentiality, in order to assign the participants into 2 different groups. Group 1 (control group) patients received RFT of the Gasserian ganglion and group 2 (Study group) patients received RFT of the peripheral branches of the trigeminal nerve.

The procedure was performed under all aseptic precautions inside the operation theater on an out- 


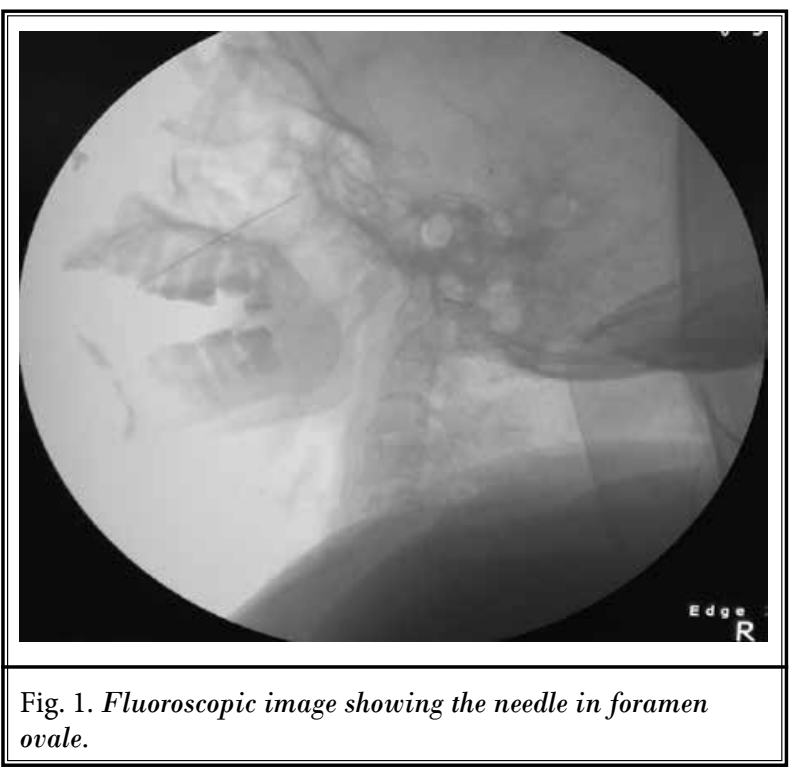

patient basis. During intervention, the patients were monitored for electrocardiogram, blood pressure, and peripheral oxygen saturation. An intravenous (IV) line was secured for the administration of fluids and drugs. Only light sedation was given with IV fentanyl $(0.5-1 \mu \mathrm{g} /$ $\mathrm{kg}$ ) or midazolam (1-2 $\mathrm{mg}$ ) in order to that the patient will respond to test stimulation when given. In control group patients, RFT of the Gasserian ganglion was performed under fluoroscopy by using the technique as described by Sweet and Wepsic (14). The patients were placed in supine position with the head in submentovertex position; after local infiltration with $2 \%$ lidocaine, a 22-gauge $10 \mathrm{~cm}$ RFA needle with $5 \mathrm{~mm}$ active tip was inserted on the affected side from a point $3 \mathrm{~cm}$ away from the angular oris and advanced towards the foramen ovale with a 30-degree caudal incline (Fig. 1). The correct position of the needle tip was confirmed by fluoroscopy and, sensory and motor stimulation test. The sensory stimulation up to 1 volt at $50 \mathrm{~Hz}$ was given until the paresthesia evoked by electrical stimulation corresponds to the location of facial pain and motor stimulation up to 2.0 volt was used to rule out any muscular contractions. After the final positioning of the needle, RFT was performed 3 times at 70 degree for 60 seconds each.

In the study group, RFT was performed according to the involvement of different divisions of the trigeminal nerve. If the pain involved 1st division, site injection was supraorbital foramen. If pain involved 2nd or 3rd division, the site of injection was foramen infraorbitale, mandibular notch or foramen mentale
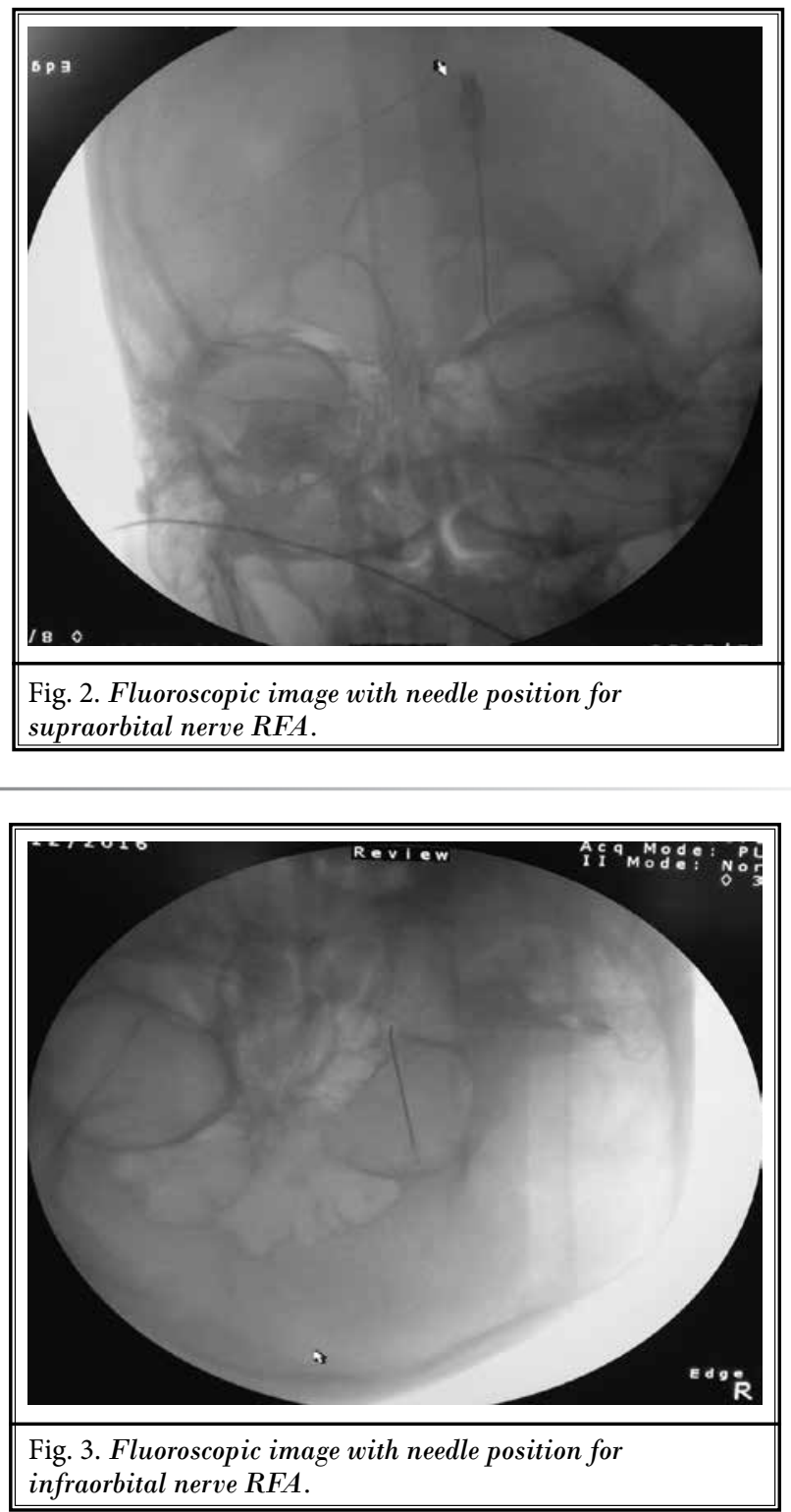

respectively. The position of the needle was confirmed using fluoroscopic imaging (Figs. 2-4) and by eliciting paresthesias corresponding to the location of pain. RFT was performed 3 times at $70^{\circ} \mathrm{C}$ for 60 seconds after ruling out any motor involvement.

One to $2 \mathrm{~mL} 2 \%$ lidocaine with $4 \mathrm{mg}$ dexamethasone was injected after the procedure before withdrawal of the needle in both the groups. The patients were assessed for loss of sensation with pin prick along the nerve distribution on the side of procedure. They were observed in the recovery room for vitals and any adverse effect for 1-2 hrs before discharge. The ad- 


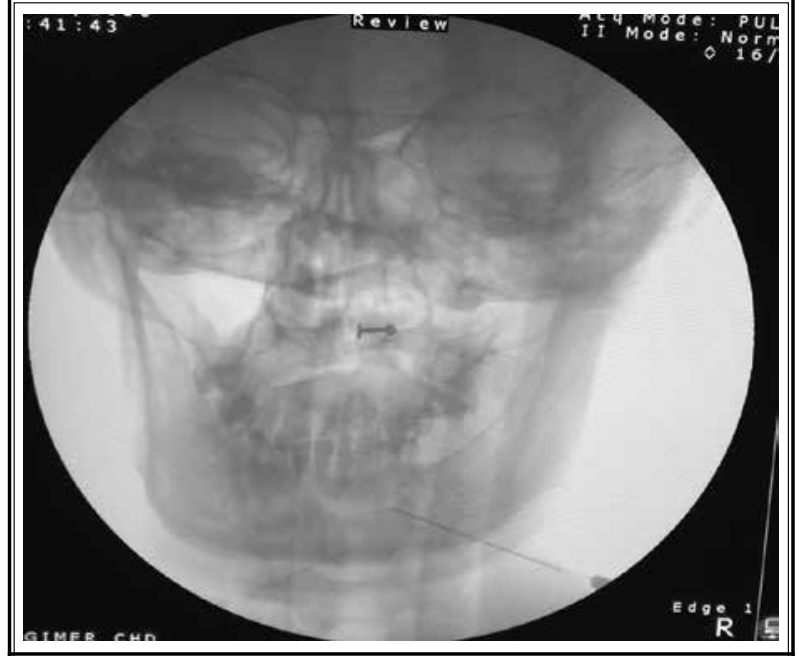

Fig. 4. Fluoroscopic image with needle position for mental nerve RFA.

equacy of pain relief was assessed on the NRS at 30 and 60 minutes. In patients with complete pain relief no medications were advised. However, in case of inadequate pain relief (NRS > 3), the patients were advised to continue their analgesic medications. Any complication like dysesthesia, masseter weakness, cheek hematoma, keratitis, cranial nerve paralysis, and any neurological deficit were recorded.

The patients were followed up at 1 week, 2 weeks, 1 month, 2 months, and 3 months post-radiofrequency at the pain clinic. During their visit, intensity of pain was assessed by the NRS and the Barrow Neurological Institute (BNI) pain intensity scale (15). Effective pain relief was considered if there was more than $50 \%$ reduction in the NRS from baseline at any point of time. Our primary outcome was the number of patients having effective pain relief for 3 months. Improvement in pain was considered excellent if patients had complete pain relief (NRS < 3) without any medication (BNI I and II), good if there was significant reduction in pain $(>50 \%)$ with or without medication (BNI III), and poor if there was less than $50 \%$ reduction in pain with medications (BNI IV and V). Patients were also assessed for presence and degree of numbness which is classified as mild (rare disturbance to daily activities), moderate (occasional disturbance to daily activities), and severe (frequent disturbance to daily activities) according to the disturbances in their daily activities. Patients' satisfaction with the procedure was assessed at the end of 3 months with a 10 -point numerical rating scale $(0=$ dissatisfied, 10 = fully satisfied).
The statistical analysis was carried out using IBM SPSS (Statistical Package for Social Sciences) statistical version 22. Normality of data was checked by Kolmogorov-Smirnov tests of normality. All quantitative variables were estimated using measures of central location (mean) and measures of dispersion (standard deviation). The means of normally distributed data were compared using unpaired Student's t-test. The nonparametric variables like pain scores were compared by Mann Whitney $U$ test. Categorical data was analyzed using the Chi-square test or the Fisher exact test. The sample size was calculated on the basis of the previous study, by assuming the efficacy of conventional radiofrequency thermoablation as $95 \%$ and peripheral division radiofrequency thermoablation as $90 \%$, we required 20 patients in each group with $80 \%$ power and $95 \%$ confidence interval.

\section{RESULTS}

A total of 40 patients of idiopathic trigeminal neuralgia were enrolled in the study (20 patients in each group) and followed up for a minimum of 3 months after the procedure. The groups were comparable for demographic variables like age, weight, gender, and duration of pain. Right side pain was more common than left side in both the groups. Most of the patients complained of lancinating or a burning type of pain in the distribution of the trigeminal nerve (Table 1).

The baseline NRS in the control and the study group was 8 (8-8) and 7.5 (7-8) [median (Inter Quartile Range)] respectively. There was a significant reduction of pain scores after the procedure in both the groups which continued until the end of 3 months (Table 2). The percentage reduction in pain at each follow-up was comparable among groups. At 3months, the pain reduction was $67 \%$ in the control group and $63 \%$ in the study group, respectively (Table 3 ). Nineteen patients in the control group and 18 patients in the study group had effective pain relief up to 3 months follow-up with or without medication (Fig. 5).

The BNI pain intensity scale was assessed under 5 grades (grade I - no pain, no medications, grade II - occasional pain, no medications, grade III - some pain, adequately controlled with medications, grade IV- some pain, not adequately controlled with medications, grade $\mathrm{V}$ - severe pain or no pain relief). The BNI scores were comparable among groups from week 1 to 3 months, except at 2 months when it was significantly better in the control group when compared to the study group (Table 4). The number of patients having 
RFA of Peripheral Branches of Trigeminal Nerve for Trigeminal Neuralgia

Table 1. Demographic data.

\begin{tabular}{|l|c|c||}
\hline \multicolumn{1}{|c|}{ Parameters } & $\begin{array}{c}\text { Control group } \\
(\mathbf{n = 2 0})\end{array}$ & $\begin{array}{c}\text { Study group } \\
(\mathbf{n = 2 0})\end{array}$ \\
\hline Age (yr) & $54.55 \pm 12.16$ & $54.40 \pm 10.07$ \\
\hline Weight (kg) & $61.35 \pm 6.78$ & $67.90 \pm 9.96$ \\
\hline Gender (M:F) & $8: 12$ & $11: 9$ \\
\hline Pain Duration (Year) & $5.04 \pm 3.35$ & $5.20 \pm 4.29$ \\
\hline Side of pain (Left : Right) & $9: 11$ & $7: 13$ \\
\hline $\begin{array}{l}\text { Nature of pain } \\
\text { (Lancinating : Burning) }\end{array}$ & $17: 3$ & $15: 5$ \\
\hline
\end{tabular}

excellent pain relief without ongoing medication was 18 in the control group and 14 in the study group at 1 month while 9 in the control group and 7 in the study group at 3 months, with no statistical significance (Table 5). However, significantly more patients in the study group required medications as compared to the control group at 2 months interval $(P=0.015)$. One patient in the control group and 2 patients in the study group had poor pain relief for which peripheral nerve blocks were supplemented. On further follow-up, the median duration of pain relief in study group was 5.5 (4-7) months and control group was $7(5-9)$ months $(P=0.13)$.

No major complications were reported in any group of patients. The baseline, intraoperative heart rate, and mean arterial pressure were comparable between the groups. No episodes of hypotension, bradycardia or hypoxia were reported. Minor side effects such as bruising, skin discoloration, swelling, and minor bleeding at the site of needle insertion were observed during
Table 2. Numeric Rating Scale (NRS) Score.

\begin{tabular}{|l|c|c|c|}
\hline Time period & $\begin{array}{c}\text { Control group } \\
(\mathbf{n}=\mathbf{2 0})\end{array}$ & $\begin{array}{c}\text { Study group } \\
(\mathbf{n}=\mathbf{2 0})\end{array}$ & P Value \\
\hline Base line & $8(8-8)$ & $7.5(7-8)$ & 0.06 \\
\hline 1 Week & $1(0.25-2)$ & $1.5(1-2)$ & 0.11 \\
\hline 2 Week & $1(0.5-2)$ & $2(1-2)$ & 0.13 \\
\hline 1 Month & $2(1-2)$ & $3(1.25-3)$ & 0.23 \\
\hline 2 Month & $2(1-2)$ & $3(1-3)$ & 0.36 \\
\hline 3 Month & $3(2-3)$ & $3(1-3)$ & 0.41 \\
\hline
\end{tabular}

Values expressed as median [median (Inter Quartile Range)].

Table 3. Percentage reduction in pain (NRS).

\begin{tabular}{||l|c|c|c||}
\hline Time period & $\begin{array}{c}\text { Control group } \\
(\mathbf{n}=\mathbf{2 0})\end{array}$ & $\begin{array}{c}\text { Study group } \\
(\mathbf{n = 2 0})\end{array}$ & P Value \\
\hline 1 Week & $89.10 \%$ & $82.88 \%$ & 0.054 \\
\hline 2 Week & $85.43 \%$ & $79.75 \%$ & 0.14 \\
\hline 1 Month & $77.33 \%$ & $67.55 \%$ & 0.12 \\
\hline 2 Month & $76.79 \%$ & $64.93 \%$ & 0.20 \\
\hline 3 Month & $66.89 \%$ & $62.98 \%$ & 0.79 \\
\hline
\end{tabular}

procedure in both the groups. One patient had lower eye lid edema, and one had mild masseter weakness in the control group, which was resolved spontaneously within 1-2 weeks. Most of the patients in both groups had mild numbness after the procedure except for 2 patients in the control group who complained of moderate numbness. Numbness of the maxillary teeth was reported in 1 patient in the study group receiving V2

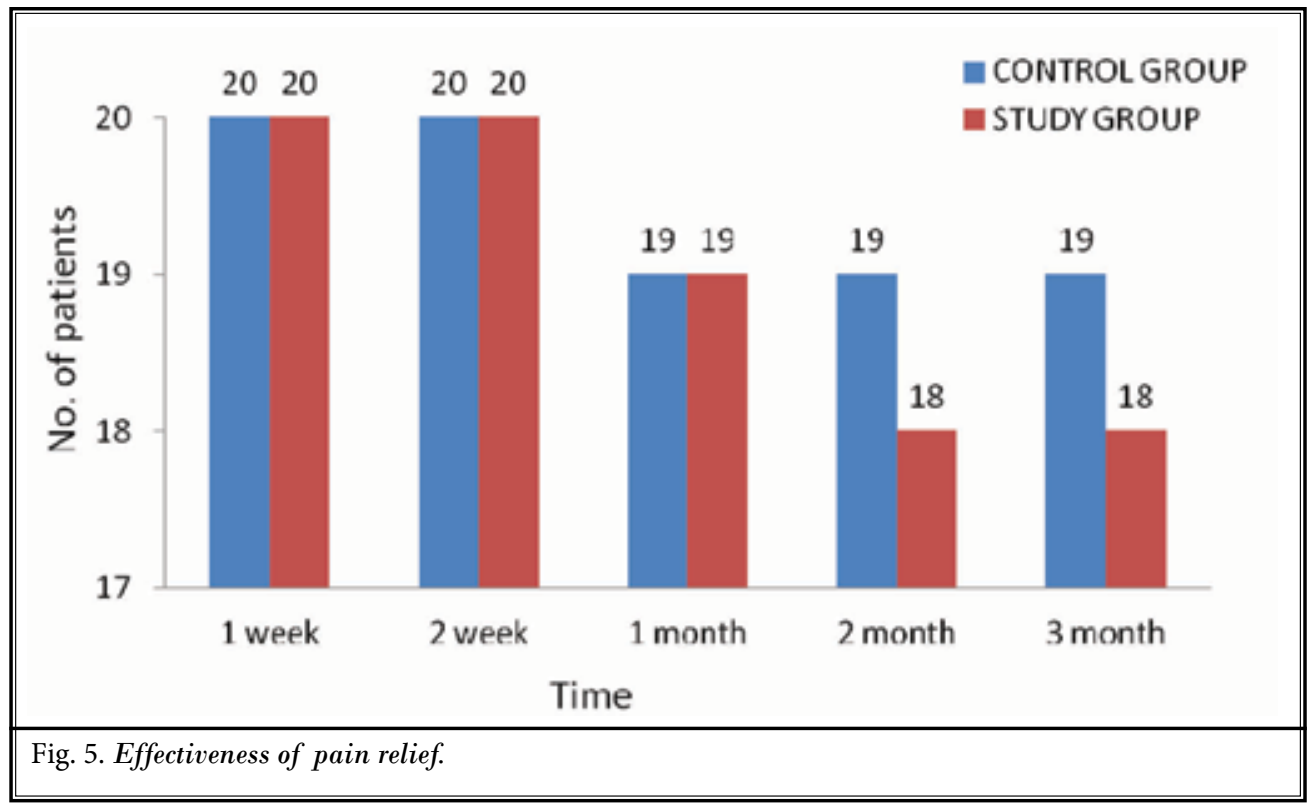


Table 4. Barrow Neurological Institute (BNI) pain intensity scale.

\begin{tabular}{|c|c|c|c|c|c|c|}
\hline \multicolumn{2}{|c|}{ Time period } & \multicolumn{2}{|c|}{$\begin{array}{c}\text { Control group } \\
(\mathbf{n}=\mathbf{2 0})\end{array}$} & \multicolumn{2}{|c|}{$\begin{array}{l}\text { Study group } \\
\quad(\mathbf{n}=\mathbf{2 0})\end{array}$} & $\begin{array}{c}P \\
\text { Value }\end{array}$ \\
\hline \multirow{2}{*}{1 Week } & BNI I-II & 19 & $95 \%$ & 19 & $95 \%$ & \multirow{2}{*}{1.0} \\
\hline & BNI III & 1 & $5 \%$ & 1 & $5 \%$ & \\
\hline \multirow{2}{*}{2 Week } & BNI I-II & 19 & $95 \%$ & 18 & $90 \%$ & \multirow{2}{*}{0.598} \\
\hline & BNI III & 1 & $5 \%$ & 2 & $20 \%$ & \\
\hline \multirow{3}{*}{1 Month } & BNI I-II & 18 & $90 \%$ & 14 & $70 \%$ & \multirow{3}{*}{0.357} \\
\hline & BNI III & 1 & $5 \%$ & 5 & $25 \%$ & \\
\hline & BNI IV & 1 & $5 \%$ & 1 & $5 \%$ & \\
\hline \multirow{3}{*}{2 Month } & BNI I-II & 15 & $75 \%$ & 8 & $40 \%$ & \multirow{3}{*}{$0.015^{\star}$} \\
\hline & BNI III & 4 & $20 \%$ & 10 & $50 \%$ & \\
\hline & BNI IV & 1 & $5 \%$ & 2 & $10 \%$ & \\
\hline \multirow{3}{*}{3 Month } & BNI I-II & 10 & $50 \%$ & 7 & $35 \%$ & \multirow{3}{*}{0.377} \\
\hline & BNI III & 9 & $45 \%$ & 11 & $55 \%$ & \\
\hline & BNI IV & 1 & $5 \%$ & 2 & $10 \%$ & \\
\hline
\end{tabular}

Data expressed as number and percentage of patients

Table 5. Quality of pain relief.

\begin{tabular}{|l|c|c|c|}
\hline & $\begin{array}{c}\text { Control group } \\
(\mathbf{n = 2 0})\end{array}$ & $\begin{array}{c}\text { Study group } \\
(\mathbf{n = 2 0})\end{array}$ & P Value \\
\hline Excellent & & & \\
1 month & 18 & 14 & 0.67 \\
2 month & 15 & 8 & 0.015 \\
3 month & 9 & 7 & 0.13 \\
\hline Good & & & \\
1 month & 1 & 5 & 0.057 \\
2 month & 5 & 10 & 0.015 \\
3 month & 10 & 11 & 0.68 \\
\hline Poor & & & \\
1 month & 1 & 1 & 1.0 \\
2 month & 1 & 2 & 0.54 \\
3 month & 1 & 2 & 0.54 \\
\hline
\end{tabular}

Data expressed as number of patients

RFT. The patients were highly satisfied with the treatment in both the groups. There was no significant difference in satisfaction scores between the groups [8.5 (8-9) and 8 (7-9) in control and study group respectively, $P=0.33$.

\section{Discussion}

Trigeminal neuralgia is a painful condition of the face with high morbidity, particularly in the elderly. The quality of life and routine functions of daily life are impaired in these patients. Employment is affected in $34 \%$ of patients and depressive symptoms are also common $(1,2)$. Most of the cases are primary or idiopathic, but it can also occur secondary to intracranial tumors and inflammatory lesions (3). Various interventional procedures like gamma knife surgery, balloon compression, glycerol lysis, and radiofrequency ablation of the Gasserian ganglion or its rootlets have been used for the treatment of patients not responding to the medical therapy or having side effects (6). Though, all these procedures were found effective, various complications like hypoesthesia, paresthesia, keratitis, muscle weakness, and anesthesia dolorosa have been reported (4-6).

Radiofrequency ablation of the peripheral branches is a relatively simple and safe procedure to perform. The ablation of the peripheral nerve, triggering the pain stimulus, would result in a conduction block of the hyperexitable axon leading to alleviation of pain. Huibin et al (10) have shown 93\% immediate pain relief after RFT of the supraorbital nerve in patients having first division ITGN. Recently, RFT of the peripheral branches of the trigeminal nerve have been tried for the treatment of various kinds of facial pains (11-13). Elahi et al (13) reported that RFT of the mental nerve has produced significant pain relief in 2 patients who presented with refractory mental neuropathy following dental extraction. In another case report, pulsed RFT of the infraorbital nerve provided excellent pain relief in a patient with post herpetic neuralgia in the V2 area of the trigeminal nerve (11). RFT of supraorbital nerve was also found effective in the resolution of headaches in patients with hemicrania continua, an uncommon primary headache disorder, where medical management was ineffective or poorly tolerated (12).

In the present study, the efficacy of RFT of the peripheral branches of the trigeminal nerve was compared with RFT of the Gasserian ganglion for the management of ITGN by evaluating the quality and duration of pain relief in both the groups. The patients were on oral medications like carbamazepine, gabapentin, pregabalin, amitryptiline, baclofen, and other non-epileptic drugs like tramadol, paracetamol with inadequate pain relief. In both groups, the procedure was performed under fluoroscopy in the operation theatre with mild sedation and standard non-invasive monitoring. The average procedural time was $30 \mathrm{~min}-$ utes (30-38) in control group and 28 minutes (25-40) in study group respectively $(P=0.40)$.

We found significant reduction in the pain scores (NRS) after procedure in both the groups. The overall reduction in pain was comparable among groups at every point of time. The BNI pain intensity index was also comparable between the groups at 1 month and 
3 months post-procedure. Nineteen patients in the control group and 18 patients in the study group had effective pain control for up to 3 months. Our efficacy of pain relief was $95 \%$ in the control group and $90 \%$ in the study group, which is comparable to the previous studies (7-10). Kanpolat et al (8) evaluated the effectiveness of percutaneous radiofrequency trigeminal rhizotomy in 1,600 patients with ITGN and reported pain relief in $92 \%$ of the patients who underwent either a single procedure or multiple procedures of RFT during 5 years. In a recent study comparing RFT of the first division branches of the trigeminal nerve with RFT of the Gasserian ganglion, Huibin et al (10) found that the immediate efficacy rates were $93 \%$ and $95 \%$ in the peripheral and the central group respectively with no significant difference on follow-up, indicating that peripheral division RFT is an effective way to treat TGN. Also, the recurrence rates of pain without medication on follow-up in 3 and 5 years were not statistically different between the groups.

In the present study, the requirement of medication was higher in the study group when compared to the control group. This may be due to the involvement of multiple peripheral nerve branches in our patients. In a retrospective study, Kosugi et al (16) examined the long-term outcome of RFT of the Gasserian ganglion for multiple divisions of TGN as compared to the isolated 2rd and 3rd division TGN in terms of immediate outcome, pain-free duration, and complications. The authors found that though the immediate outcome was similar, the pain-free duration was more in the isolated 3rd division TGN as compared to multiple division TGN $(P=0.012)$.

Various complications have been observed in patients receiving Gasserian ganglion RFT including diminished corneal reflex, masseter weakness and paralysis, dysesthesia, anesthesia dolorosa, keratitis, and transient paralysis of Cranial Nerves III and VI (8). We did not encounter any major complications in either group of patients, except transient lower eyelid edema in 1 patient and masseter weakness in 1 patient in the control group that resolved spontaneously. The problem was only mild (difficulty in clenching of teeth) and there was no impairment to his daily activities like eating and talking.

\section{Limitations}

The main limitation of our study was that the patients and the anesthesiologist who performed the procedures were not blinded, though the person who assessed the patient during follow-up was blinded to the group assignment.

\section{Conclusion}

In conclusion, peripheral nerve branches RFT is a simple and safe technique and equally effective as Gasserian ganglion RFT for the management of ITGN. We found that there was no significant difference in the efficacy and quality of pain relief among the study and control groups as assessed by the percentage reduction of the NRS from preprocedure value and the Barrow Neurological Institute pain intensity scale. Also, both the techniques significantly reduced the consumption of medications and were equally satisfactory to the patients. Though, further multicentric long-term followup studies are required to establish the efficacy of the peripheral branches radiofrequency thermoablation for the management of idiopathic trigeminal neuralgia.

\section{Author Contributions}

Drs. Neerja Bharti and John Sujith had full access to all the data in the study and take responsibility for the integrity of the data and the accuracy of the data analysis. Drs. Neerja Bharti and Navneet Singla designed the study protocol. Dr. John Sujith managed the literature searches and summaries of previous related work and wrote the first draft of the manuscript. Drs. Indu Bala and Nidhi Panda provided revision for intellectual content and final approval of the manuscript. 


\section{References}

1. Tölle T, Dukes E, Sadosky A. Patient burden of trigeminal neuralgia: Results from a cross-sectional survey of health state impairment and treatment patterns in six European countries. Pain Pract 2006; 6:153-160.

2. Katusic S, Beard CM, Bergstralh E, Kurland LT. Incidence and clinical features of trigeminal neuralgia, Rochester, Minnesota 1945-1984. Ann Neurol 1990; 27:89-95.

3. Love S, Coakham HB. Trigeminal neuralgia pathology and pathogenesis. Brain 2001; 12:2347-2360.

4. Cruccu G, Gronseth G, Alksne J, Argoff C, Brainin M, Burchiel K, Nurmikko T, Zakrzewska JM. AAN-EFNS guidelines on trigeminal neuralgia management. Eur J Neurol 2008; 15:1013-1028.

5. Montano N, Conforti G, Di Bonaventura R, Meglio M, Fernandez E, Papacci F. Advances in diagnosis and treatment of trigeminal neuralgia. Ther Clin Risk Manag 2015; 11:289-299.

6. Cheng JS, Lim DA, Chang EF, Barbaro NM. A review of percutaneous treatments for trigeminal neuralgia. Neurosurgery 2014; 10 Suppl 1:25-33.
7. Onofrio BM. Mayo Clinic and Mayo Foundation, Rochester, Minnesota, Radiofrequency percutaneous Gasserian ganglion lesions. J Neurosurg 1975; 42:132-139.

8. Kanpolat $Y$, Savas A, Bekar A, Berk C. Percutaneous controlled radiofrequency trigeminal rhizotomy for the treatment of idiopathic trigeminal neuralgia: 25-year experience with 1600 patients. Neurosurgery 2001; 3:524-534.

9. Erdine S, Ozyalcin NS, Cimen A, Celik M, Talu GK, Disci R. Comparison of pulsed radiofrequency with conventional radiofrequency in the treatment of idiopathic trigeminal neuralgia. Eur J Pain 2007; 11:309-313.

10. Huibin $Q$, Jianxing L, Guangyu H, Dianen $F$. The treatment of first division idiopathic trigeminal neuralgia with radiofrequency thermocoagulation of the peripheral branches compared to conventional radiofrequency. J Clin Neurosci 2009; 16:1425-1429.

11. Lim SM, Park HL, Moon HY, Kang KH, Kang $\mathrm{H}$, Baek CH, Jung YH, Kim JY, Koo $\mathrm{GH}$, Shin HY. Ultrasound-guided in- fraorbital nerve pulsed radiofrequency treatment for intractable postherpetic neuralgia. Korean J Pain 2013; 26:84-88.

12. Weyker P, Webb C, Mathew L. Radiofrequency ablation of the supra-orbital nerve in the treatment algorithm of hemicrania continua. Pain Physician 2012; 15:719-724.

13. Elahi F, Manolitsis N, Ranganath YS, Reddy C. Mental nerve neuropathy following dental extraction. Pain Physician 2014; 17:375-380.

14. Sweet WH, Wepsic JG. Controlled thermocoagulation of trigeminal ganglion and rootlets for differential destruction of pain fibres. J Neurosurg 1974; 40:143-156.

15. Chen HI, Lee JYK. The Measurement of Pain in Patients with Trigeminal Neuralgia. Clin Neurosurg 2010; 57:129-33.

16. Kosugi S, Shiotani M, Otsuka Y, Suzuki T, Katori N, Hashiguchi S, Morisaki H. Long-term outcomes of percutaneous radiofrequency thermocoagulation of the Gasserian ganglion for 2nd- and multiple-division trigeminal neuralgia. Pain Practice 2015; 15:223-228. 